\title{
Media Sosial dan Perilaku Konsumtif
}

\author{
Charissa Fransisca, Rezi Erdiansyah \\ charissafransisca5@gmail.com,rezie@fikom.untar.ac.id ${ }^{2}$ \\ Fakultas Ilmu Komunikasi Universitas Tarumanagara
}

\begin{abstract}
The purpose of this study was to determine whether there is an influence between social media on consumer behavior. The population used in this study is the millennial with the age of 17-25 years with a total sample of 150 respondents and indicators of 30 statements. Test the validity and reliability using SPSS 15 and data analysis using the Lisrel 8.70 application. Data collection techniques using questionnaires as primary data, and journals and books as secondary data. The results show that social media has a significant effect on consumptive behavior with the highest dimension is conversation with a value of 0.94, then followed by an openness dimension with a value of 0.89 , then the community dimension with a value of 0.81 , the dimension of perception with a value of 0.68 , and dimensions are associated with values of 1.07. So it can be concluded that the intensity of the conversation carried out on social media can affect whether the person behaves consumptively or not. The intensity of the conversation in question is in the form of exchanging information through social media, or asking friends for opinions on social media.
\end{abstract}

Keywords: consumptive behavior, millennial, social media.

\begin{abstract}
Abstrak
Tujuan penelitian ini adalah untuk mengetahui apakah terdapat pengaruh antara media sosial terhadap perilaku konsumtif. Populasi yang digunakan dalam penelitian ini adalah kaum milenial dengan usia 17-25 tahun dengan jumlah sampel sebanyak 150 responden dan indikator sebanyak 30 pernyataan. Uji validitas dan reliabilitas menggunakan SPSS 15 dan analisis data menggunakan aplikasi Lisrel 8.70 . Teknik pengumpulan data menggunakan angket sebagai data primer, serta jurnal dan buku sebagai data sekunder. Hasil menunjukkan bahwa media sosial berpengaruh signifikan terhadap perilaku konsumtif dengan dimensi yang paling tinggi yaitu perbincangan dengan nilai 0,94 , lalu diikuti oleh dimensi keterbukaan dengan nilai 0,89 , kemudian dimensi komunitas dengan nilai 0,81 , dimensi persepsi dengan nilai 0,68 , dan dimensi terhubungkan dengan nilai 1,07. Sehingga dapat disimpulkan bahwa intensitas perbincangan yang dilakukan di media sosial dapat memengaruhi apakah orang tersebut berperilaku konsumtif atau tidak. Intensitas perbincangan yang dimaksud berupa tukar menukar informasi melalui media sosial, atau menanyakn pendapat teman di sosial media.
\end{abstract}

Kata Kunci: millennial, media sosial, perilaku konsumtif. 


\section{Pendahuluan}

Perkembangan globalisasi berkembang sangat pesat mulai dari teknologi, mode pakaian, restaurant, dan fashion. Media sosial menjadi salah satu dari perkembangan teknologi yang menjadi favorit bagi kaum milenial dengan mengakses informasi menggunakan internet. Indonesia menjadi salah satu negara dengan pengguna media sosial terbanyak dengan jumlah 56\% dari total populasi penduduk Indonesia yaitu 150 juta jiwa (https://websindo.com/indonesia-digital-2019-media-

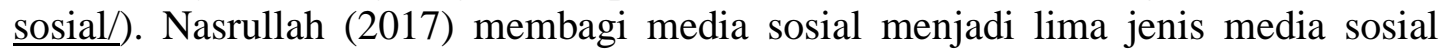
yaitu social Networking, blog, microblogging, media sharing, dan social bookmarking.

Media sosial banyak diminati hampir dari semua kalangan mulai dari anakanak, remaja, orang dewasa, bahkan orang tua. Munculnya media sosial mengenalkan individu kepada dunia yang lebih luas seperti informasi maupun teknologi yang terus berkembang yang mampu membentuk persepsi mereka untuk mengikuti segala bentuk perubahan yang terjadi, dan apabila mereka tidak mengikuti arus modernisasi tersebut maka mereka dinilai tidak siap terjun dan pasif dalam era globalisasi. Seperti yang dikemukakan Hana Nur et al. (2019), Media sosial menjadi kebutuhan primer yang tidak terbatas oleh waktu, ruang, usia bahkan pekerjaan. Menurut Utami, et al., remaja saat ini lebih memilih berbelanja menggunakan media sosial karena hanya dengan mengklik kemudian transfer maka barang yang dipesan akan datang sendiri ke rumah.

Adanya media sosial mendorong seseorang berperilaku konsumtif, berawal dari melihat profil atau snapgram yang diunggah oleh teman di sosial media dapat membuat rasa iri dan keinginan untuk mengejar kepuasaan dalam diri orang tersebut. Sehingga menurut Amaliya (2017), media sosial menjadi ajang pamer bagi kebanyakan orang.

Perilaku konsumtif merupakan keinginan seseorang untuk mengkonsumsi suatu barang atau jasa secara berlebihan untuk mencapai kepuasan (Tambunan, 2001). Sedangkan menurut Sumartono (2002) perilaku konsumtif merupakan tindakan membeli suatu barang tanpa pertimbangan yang masuk akal dan tidak didasari pada faktor kebutuhan. Sehingga dapat ditarik kesimpulan bahwa perilaku konsumtif adalah perilaku seseorang yang membeli barang yang didasarkan pada rasio dan keinginannya yang kurang diperlukan sehingga menjadi berlebihan untuk mencapai kepuasan maksimal. Zaman dulu, orang berbelanja untuk memenuhi kebutuhan primer dan sekunder namun saat ini orang berbelanja cenderung untuk menyenangkan diri sendiri, memuaskan keinginan, serta lebih mementingkan faktor keinginan dibandingkan kebutuhan. Perilaku konsumtif dipengaruhi oleh faktor eksternal dan internal seseorang.

Menurut Lina dan Rosyid (Amaliya, 2017), perilaku konsumtif seseorang ditandai dengan kehidupan mewah dan berlebihan. Untuk memenuhi perilaku konsumtif memerlukan biaya yang tidak sedikit, penggunaan segala hal yang dianggap paling mahal mampu memberikan kepuasan dan kesenangan bagi orang yang menganutnya. Perilaku Konsumtif dilakukan untuk menunjukkan status sosial, kekayaan, prestige, dan untuk mendapatkan kepuasan bagi penganutnya. Terbentuknya perilaku konsumtif sudah menjadi bagian dari proses gaya hidup seseorang. Adapun lina dan Rosyid (Lestarina et al., 2017) membagi aspek perilaku konsumtif menjadi tiga yaitu pembelian impulsif, pemborosan dan mencari kesenangan. 
Kelompok pada usia remaja merupakan salah satu penganut perilaku konsumtif karena para rema dinilai masih kurang percaya diri dan labil serta belum mampu menentukan kebutuhan dan keinginan yang perlu dikonsumsi atau tidak sehingga remaja menyukai hal-hal menyenangkan dan boros dalam menggunakan uang jajannya. Sesuai dengan Gumulya dan Mariyana (2012) bahwa Masa remaja merupakan masa pencarian jati diri dan terjadi proses pembentukan perilakunya. Para remaja pun rela merogohkan kantong lebih agar mendapatkan barang yang mereka ingini walaupun harganya mahal. Hal ini terbukti dari kebiasaan para remaja yang lebih menyukai membelanjakan uang jajan nya untuk barang-barang yang masih ada atau layak digunakan dan meluangkan banyak waktu untuk jalan-jalan ke mall.

\section{Metode Penelitian}

Metode penelitian pada penelitian ini yaitu menggunakan penelitian kuantitatif dengan tujuan agar hasil penelitian yang dicapai tidak menyimpang dari data sesungguhnya dan reliabel serta untuk mengetahui hubungan sebab akibat antara media sosial terhadap perilaku konsumtif. Teknik pengumpulan data pada penelitian ini dengan menyebarkan kuesioner secara online dengan menggunakan google form untuk mendapatkan informasi secara langsung dari responden yang dituju.

Populasi pada penelitian ini merupakan kaum milenial yang tersebar di Jakarta Barat dengan usia antara 17 tahun sampai 25 tahun. Dalam menentukan sampel penulis menggunakan Hair et al., (Aryani dan Rosinta, 2010) yaitu banyaknya responden yang diteliti berdasarkan banyaknya jumlah indikator yang digunakan dikali 5. Menurut Sugiyono (Dennyka, dan Erdiansyah, 2017) Ukuran sampel lebih harus dari 30 dan kurang dari 500 adalah tepat untuk kebanyakan penelitian. Indikator pada penelitian ini sebanyak 30 indikator, 30x $5=150$ responden sebagai dasar minimal responden penelitian.

Skala pengukuran yang digunakan yaitu skala Likert dengan skala dari 1-5. Dengan metode pengumpulan data dengan sekunder dan primer. Dalam menguji validitas dan reliabel pada penelitian ini menggunakan SPSS 15 sedangkan untuk menguji hipotesis menggunakan Lisrel 8.70 .

\section{Hasil Temuan dan Diskusi}

Penelitian ini disebarkan sejak 4 Oktober 2019 sampai dengan 12 Oktober 2019 dengan total responden yaitu 150 responden dan diketahui bahwa pada penelitian ini terdapat sebanyak 96 responden berjenis kelamin perempuan dan 54 responden berjenis kelamin laki-laki dengan usia terbesar yaitu 20 sampai 21 tahun dengan persentase $56 \%$ dan jatah uang bulanan Rp. 1.000.000,- sampai Rp. 2.000.000,- dipilih sebanyak 64 responden dengan persentase $42.7 \%$.

Dalam media sosial terdapat lima dimensi yang memengaruhi media sosial yaitu partisipasi, keterbukaan, perbincangan, komunitas, dan terhubungkan. Dalam lima dimensi yang memengaruhi media sosial, nilai yang paling tinggi dalam memengaruhi media sosial adalah perbincangan dengan nilai 0,94 . Peneliti kemudian membagi dimensi perbincangan dalam dua indikator yaitu MS6 dan MS7, dan nilai indikator yang paling tinggi dalam memengaruhi dimensi perbincangan adalah MS7 dengan pernyataan "sering bertanya pendapat followers atau teman-teman di media sosial tentang suatu hal" lalu diikuti indikator MS6 dengan pernyataan "sering berinteraksi (mengirim dan membalas pesan) dengan followers atau teman-teman di media sosial" yang bernilai 0,64 . 
Dari penjelasan diatas dapat disimpulkan bahwa intensitas perbincangan yang dilakukan di media sosial dapat memengaruhi perilaku konsumtif seseorang. Jadi, semakin tinggi intensitas perbincangan pada media sosial maka semakin tinggi pula perilaku konsumtifnya. Intensitas perbincangan dalam media sosial yang dimaksud adalah tukar menukar informasi, atau menanyakan pendapat teman-teman di media sosial karena media sosial memiliki fungsi mutlak untuk berkomunikasi dan mampu mempersuasi, lalu dari komunikasi tersebut dapat memengaruhi seseorang untuk mengikuti apa yang sedang tren sehingga menimbulkan perilaku yang konsumtif. Media sosial memberikan kontribusi yang cukup besar untuk memengaruhi seseorang dengan cara menampilkan tren-tren bergaya ataupun berbusana sehingga remaja lain yang melihat di media sosial atau terbujuk oleh teman-temannya akan mengikuti gaya hidup tersebut. Hasil penelitian ini sependapat dengan penelitian yang dilakukan oleh Utami et al (2018) dan Sofia Miranda (2016) yang menunjukkan teori hasil signifikan positif media sosial terhadap perilaku konsumtif.

Pada perilaku konsumtif dibagi menjadi empat dimensi yaitu pemenuhan keinginan, barang di luar jangkauan, barang cenderung tidak produktif, dan status. Dimensi yang paling tinggi yaitu status dengan nilai 0,93 kemudian diikuti oleh dimensi barang di luar jangkauan, pemenuhan keinginan, dan barang cenderung tidak produktif.Dapat disimpulkan bahwa perilaku konsumtif paling dipengaruhi oleh faktor internal didalam diri orang tersebut yaitu untuk mendapatkan penghargaan diri dan pengakuan dari orang-orang di sekitarnya. Semakin mahal dan bermerek produknya maka semakin tinggi pula kepercayaan dirinya. Didukung dengan hasil penelitian Patricia, dan Handayani (2014) bahwa perilaku konsumtif dipengaruhi status dan gengsi.

\section{Simpulan}

Berdasarkan dari hasil penelitian, peneliti menyimpulkan bahwa terdapat pengaruh yang signifikan antara media sosial terhadap perilaku konsumtif dengan nilai 0,38 dan dimensi yang paling memengaruhi perilaku konsumtif seseorang adalah intensitas perbincangan yang dilakukan pada media sosial yaitu sebesar 0,94.

\section{Ucapan Terima Kasih}

Penulis mengucapkan terima kasih kepada seluruh pihak yang telah membantu proses penelitian dan penulisan artikel ini, terutama kepada responden yang telah membantu dalam menyelesaikan penelitian ini.

\section{Daftar Pustaka}

Amaliya, Luthfatul,. \& Khasan S.. (2017). "Pengaruh Penggunaan Media Sosial Instagram, Teman Sebaya dan Status Sosial Ekonomi Orang Tua Terhadap Perilaku Konsumtif Siswa (Studi Kasus pada Siswa Kelas XI SMA Negeri 1 Semarang)". Economic Education Analysis Journal 6 (3), 835-842.

Dennyka, \& Rezi Erdiansyah. (2017). "Pengaruh Daya Tarik Iklan Mobile Legends di Youtube Terhadap Keputusan Pembelian Karakter Game Mobile Legends". Prologia, 1, 345-350. 
Gumulya, Jessica,. \& Mariana W,. (2013). "Pengaruh Konsep Diri Terhadap Perilaku Konsumtif Mahasiswa Universitas Esa Unggul”. Jurnal Psikologi, Vol. 11, 1, $50-65$.

Lestarina, et al,. (2017). "Perilaku Konsumtif di Kalangan Remaja". Jurnal Riset Tindakan Indonesia, Vol. 2, 2, 1-6.

Miranda, Sofia. (2017). "Pengaruh Instagram Sebagai Media Online Shopping Terhadap Perilaku Konsumtif Mahasiswi Fakultas Ilmu Sosial dan Ilmu Politik Universitas Riau”. JOM FISIP Vol.4 (1), 1-15.

Nasrullah, Rulli. (2017). Media Sosial : Perspektif Komunikasi, Budaya, dan Sosioteknologi. Bandung:Remaja Rosdakarya.

Patricia, N. L, \& Sri Handayani. (2014). "Pengaruh Gaya Hidup Hedonis terhadap Perilaku Konsumtif pada Pramugari Maskapai Penerbangan "X". Jurnal Psikologi, Vol. 12, 1,10-16.

Sumartono. (2002). Terperangkap dalam Iklan (Meneropong Imbas Pesan Iklan Televisi. Bandung: Alfabeta.

Tambunan, R. (2001). Remaja dan Pola Hidup Konsumtif. Jurnal Psikologi (Online). www.e-psikologi.com

Utami, Erlina R., \& Albet M. (2019). "Pengaruh Instagram, Kelompok Teman Sebaya, Literasi Ekonomi, dan lifestyle terhadap perilaku konsumtif". JEE, Vol. $7,2$.

Websindo.com. (2019, 7 Maret). Indonesia Digital 2019: Media Sosial. Diakses pada 23 Oktober 2019, dari https://websindo.com/indonesia-digital-2019-mediasosiall 